Brit. J. vener. Dis. (1957), 33, 78.

\title{
PROBLEMS OF VENEREAL DISEASE CONTROL IN POLAND*
}

\author{
BY \\ JÓZEF TOWPIK \\ Institute of Dermatology and Venereology, Warsaw, Poland
}

As in many other countries, a considerable increase in venereal disease was observed in Poland after the second world war. Poland was twice the scene of war and also had five years of German military occupation; she suffered particularly from all the deplorable effects of war, and the health of her population was badly affected. Syphilis and gonorrhoea morbidity attained a high level never before observed in Poland and, in 1947, reached a rate of 50 and 24 cases respectively per 10,000 population.

\section{Legislation and Organization}

In 1946 a law was passed giving official authorization for planning an anti-venereal campaign. One of the most important provisions of this law was the compulsory and free treatment of venereal diseases. Preparatory measures included a considerable increase in dispensaries with adequate diagnostic equipment, and the training of physicians and auxiliary staff in the modern treatment and control of venereal diseases. In 1948, a nation-wide campaign, based on new methods of treatment with penicillin, was carried out. Modern epidemiological principles were introduced (e.g., obligatory case and contact reporting, contact investigation, mass serologic examination of large groups of the population, obligatory examination of pregnant women, obligatory treatment and follow-up of infected persons) and have subsequently been adopted as an established way of fighting venereal disease.

In Poland, venereology and dermatology constitute a single branch of the medical profession. Thus, the existing dispensary system must cope simultaneously with venereal diseases and skin diseases of social importance, especially fungus infection, skin tuberculosis, pyoderma, and industrial skin disease. The work of rural and county dispensaries is supervised by the main provincial dispensaries whose duty

* Invited àrticle received for publication February 6, 1957. it is to register cases of venereal infection, collect statistical data for each province, consult in doubtful cases, and run consultative dispensaries for late syphilis and centres for serological, analytical, and bacteriological tests.

Since 1949, one of the departments of the Institute of Dermatology and Venereology in Warsaw has given a scientific lead in fighting venereal diseases and social skin diseases, as well as collecting and arranging statistical data from the whole of Poland; this has been from the point of view of organization and not of administration. The Institute is a scientific centre equipped with clinical and research laboratories. It fulfils an advisory and consultative function for the Ministry of Health, and all important problems from the field of dermatology and venereology are discussed by its Scientific Council, which includes professors and specialists from the whole of Poland.

\section{Results of Venereal Disease Campaign}

The results of the campaign against venereal disease in Poland between 1947 and 1955 (Table) show a considerable fall in the morbidity rates for syphilis and gonorrhoea during the first three years 1948,1949 , and 1950 . The morbidity rate for gonorrhoea, which had fallen 50 per cent. by 1950 , has since risen very slightly.

TABLE

VENEREAL DISEASE RATE PER 10,000 POPULATION IN POLAND FOR THE PERIOD 1947-1955

\begin{tabular}{c|c|c}
\hline Year & $\begin{array}{c}\text { Syphilis Primary, } \\
\text { Secondary, and } \\
\text { Congenital }\end{array}$ & Gonorrhoea \\
\hline 1947 & $\pm 50 \cdot 0$ & $24 \cdot 0$ \\
1948 & $24 \cdot 3$ & $18 \cdot 0$ \\
1949 & $6 \cdot 89$ & $13 \cdot 0$ \\
1950 & $2 \cdot 48$ & $12 \cdot 64$ \\
1951 & $1 \cdot 44$ & $13 \cdot 42$ \\
1952 & $1 \cdot 11$ & $14 \cdot 20$ \\
1953 & $0 \cdot 81$ & $14 \cdot 59$ \\
1954 & $0 \cdot 80$ & $14 \cdot 34$ \\
1955 & $0 \cdot 97$ & $14 \cdot 76$ \\
\hline
\end{tabular}


A similar epidemiological situation has been observed in a number of other countries. It seems that a relatively high morbidity rate for gonorrhoea does not permit too optimistic an outlook for the future. The possibility of a rise in the morbidity rate for syphilis also exists.

The sudden fall of the morbidity rate in venereal disease, particularly in the initial period, was undoubtedly due to the wide application of antibiotics in their treatment. However, antibiotics have not solved the problem entirely, and, unfortunately, they have brought about an essential change in the psychology of the patients and the population, more especially in the attitude of young people to the venereal diseases. Fear of infection is not so strong as it used to be, which fact leads the individual to neglect the disease and prophylactic measures. Lack of cooperation on the part of patients is another important factor in contact investigation and contact tracing.

The campaign against venereal disease in Poland has not been limited only to prophylactic measures and treatment of new cases; another objective has been the prevention of late syphilis in persons previously infected. The problem of how to prevent late syphilis, i.e., adequate diagnosis and treatment of patients with late latent and systemic syphilis, has been important from the very beginning of the campaign. Using Chediak's test, over 9 million people were examined by mass serological examinations from 1948 to 1954; suitable propaganda has resulted in an influx of patients who had been infected with syphilis in preceding years without knowing it, and of others, who although conscious of the fact, were treated either insufficiently or not at all. For the solution of the different and often complicated clinical problems of late syphilis, team work by separate medical specialists is desirable and provision was therefore made for the patients to undergo, free of cost, all the tests and examinations necessary for establishing a precise and complete diagnosis, i.e. an $x$-ray picture of the thorax, examinations by a physician (cardiovascular system), an oculist, and a neurologist, and, finally, an examination of the cerebro-spinal fluid. To cope with the task, special examination centres in each district were organized at the main dermato-venereological dispensary.

The results of the examinations by various specialists and of the cerebrospinal fluid test, together with the whole history of the patient, were analysed by a syphilologist who then decided the course of treatment. This system of examining patients with late syphilis is valuable because it helps to prevent late systemic changes in latent cases and provides early and adequate treatment for symptomatic cases. 